Internat. J. Math. \& Math. Sci.

Vol. 23, No. 12 (2000) 815-818

S0161171200003033

(c) Hindawi Publishing Corp.

\title{
ON A NEW GENERALIZATION OF ALZER'S INEQUALITY
}

\section{FENG QI and LOKENATH DEBNATH}

(Received 2 April 1999 and in revised form 10 December 1999)

ABSTRACT. Let $\left\{a_{n}\right\}_{n=1}^{\infty}$ be an increasing sequence of positive real numbers. Under certain conditions of this sequence we use the mathematical induction and the Cauchy mean-value theorem to prove the following inequality:

$$
\frac{a_{n}}{a_{n+m}} \leq\left(\frac{(1 / n) \sum_{i=1}^{n} a_{i}^{r}}{(1 /(n+m)) \sum_{i=1}^{n+m} a_{i}^{r}}\right)^{1 / r},
$$

where $n$ and $m$ are natural numbers and $r$ is a positive number. The lower bound is best possible. This inequality generalizes the Alzer's inequality (1993) in a new direction. It is shown that the above inequality holds for a large class of positive, increasing and logarithmically concave sequences.

Keywords and phrases. Alzer's inequality, logarithmically concave sequence.

2000 Mathematics Subject Classification. Primary 26D15.

1. Introduction. Several authors including Alzer [1], Sandor [8], and Ume [10] proved the following inequality:

$$
\frac{n}{n+1}<\left(\frac{(1 / n) \sum_{i=1}^{n} i^{r}}{(1 /(n+1)) \sum_{i=1}^{n+1} i^{r}}\right)^{1 / r},
$$

where $r>0$ and $n \in \mathbb{N}$. The proof of this inequality involves the principle of the mathematical induction and other analytical methods.

Based on the mathematical induction, Elezović and Pečarić [2] generalized (1.1) and proved the following theorem.

THEOREM 1.1. If the sequence $\left\{a_{n}\right\}_{n=1}^{\infty}$ of positive real numbers satisfies the inequality

$$
1 \leq\left(\frac{a_{n+2}}{a_{n+1}}\right)^{r}\left[\frac{a_{n+2}}{a_{n+1}}-1+\left(\frac{a_{n}}{a_{n+1}}\right)^{r+1}\right], \quad n \geq 0, a_{0}=0,
$$

then the following inequality holds:

$$
\frac{a_{n}}{a_{n+1}} \leq\left(\frac{\left(1 / a_{n}\right) \sum_{i=1}^{n} a_{i}^{r}}{\left(1 / a_{n+1}\right) \sum_{i=1}^{n+1} a_{i}^{r}}\right)^{1 / r} .
$$

Recently, Qi [4] proved a generalized version of (1.1). The reader is referred to [4, Corollary 2].

The main purpose of this paper is to further generalize inequalities (1.1) and (1.3). 


\section{Main Results}

THEOREM 2.1. Let $n$ and $m$ be natural numbers. Suppose $\left\{a_{1}, a_{2}, \ldots\right\}$ is a positive and increasing sequence satisfying

$$
\frac{(k+2) a_{k+2}^{r}-(k+1) a_{k+1}^{r}}{(k+1) a_{k+1}^{r}-k a_{k}^{r}} \geq\left(\frac{a_{k+2}}{a_{k+1}}\right)^{r}
$$

for any given positive real number $r$ and $k \in \mathbb{N}$, then we have the inequality

$$
\frac{a_{n}}{a_{n+m}} \leq\left(\frac{(1 / n) \sum_{i=1}^{n} a_{i}^{r}}{(1 /(n+m)) \sum_{i=1}^{n+m} a_{i}^{r}}\right)^{1 / r} .
$$

The lower bound of (2.2) is best possible.

Proof. The inequality (2.2) is equivalent to

$$
\frac{a_{n}^{r}}{a_{n+m}^{r}} \leq \frac{(1 / n) \sum_{i=1}^{n} a_{i}^{r}}{(1 /(n+m)) \sum_{i=1}^{n+m} a_{i}^{r}}
$$

that is,

$$
\frac{1}{n a_{n}^{r}} \sum_{i=1}^{n} a_{i}^{r} \geq \frac{1}{(n+m) a_{n+m}^{r}} \sum_{i=1}^{n+m} a_{i}^{r} .
$$

This is also equivalent to

$$
\frac{1}{n a_{n}^{r}} \sum_{i=1}^{n} a_{i}^{r} \geq \frac{1}{(n+1) a_{n+1}^{r}} \sum_{i=1}^{n+1} a_{i}^{r} .
$$

Since

$$
\sum_{i=1}^{n+1} a_{i}^{r}=\sum_{i=1}^{n} a_{i}^{r}+a_{n+1}^{r}
$$

inequality (2.5) reduces to

$$
\sum_{i=1}^{n} a_{i}^{r} \geq \frac{n a_{n}^{r} a_{n+1}^{r}}{(n+1) a_{n+1}^{r}-n a_{n}^{r}}
$$

It is easy to see that inequality (2.7) holds for $n=1$.

Assume that inequality (2.7) holds for $n>1$. Using the principle of induction, it is easy to show that (2.7) holds for $n+1$. Using equality (2.6), the induction can be written as (2.1) for $k=n$. Thus, inequality (2.7) holds.

It can easily be shown that

$$
\lim _{r \rightarrow+\infty}\left(\frac{(1 / n) \sum_{i=1}^{n} a_{i}^{r}}{(1 /(n+m)) \sum_{i=1}^{n+m} a_{i}^{r}}\right)^{1 / r}=\frac{a_{n}}{a_{n+m}} .
$$

Hence, the lower bound of (2.2) is best possible. The proof is complete. 
COROLLARY 2.2. Let $n$ and $m$ be natural numbers. Suppose $a=\left\{a_{1}, a_{2}, \ldots\right\}$ is $a$ positive and increasing sequence satisfying

$$
\begin{gathered}
a_{k+1}^{2} \geq a_{k} a_{k+2}, \\
\frac{a_{k+1}-a_{k}}{a_{k+1}^{2}-a_{k} a_{k+2}} \geq \max \left\{\frac{k+1}{a_{k+1}}, \frac{k+2}{a_{k+2}}\right\}, \quad k \in \mathbb{N} .
\end{gathered}
$$

Then, for any given positive real number $r$, we have the inequality (2.2). The lower bound of (2.2) is best possible.

Proof. For $x \in[n, n+1]$, let

$$
\begin{aligned}
& f(x)=(n+1-x) a_{n+1}+(x-n) a_{n+2}, \\
& g(x)=(n+1-x) a_{n}+(x-n) a_{n+1} .
\end{aligned}
$$

Further, we define

$$
F(x)=(x+1) f^{r}(x), \quad G(x)=x g^{r}(x), \quad x \in[n, n+1] .
$$

Direct calculation yields

$$
\begin{aligned}
F(n) & =(n+1) a_{n+1}^{r}, \quad F(n+1)=(n+2) a_{n+2}^{r} ; \\
G(n) & =n a_{n}^{r}, \quad G(n+1)=(n+1) a_{n+1}^{r} ; \\
F^{\prime}(x) & =f^{r-1}(x)\left[f(x)+r(x+1)\left(a_{n+2}-a_{n+1}\right)\right] ; \\
G^{\prime}(x) & =g^{r-1}(x)\left[g(x)+r x\left(a_{n+1}-a_{n}\right)\right] .
\end{aligned}
$$

Therefore, using the inequality (2.10) and standard arguments gives

$$
\begin{aligned}
\frac{F^{\prime}(x)}{G^{\prime}(x)}= & \left(\frac{(n+1-x) a_{n+1}+(x-n) a_{n+2}}{(n+1-x) a_{n}+(x-n) a_{n+1}}\right)^{r} \\
& \times \frac{1+r(x+1)\left(a_{n+2}-a_{n+1}\right) /\left[(n+1-x) a_{n+1}+(x-n) a_{n+2}\right]}{1+r x\left(a_{n+1}-a_{n}\right) /\left[(n+1-x) a_{n}+(x-n) a_{n+1}\right]} \\
\geq & \left(\frac{(n+1-x) a_{n+1}+(x-n) a_{n+2}}{(n+1-x) a_{n}+(x-n) a_{n+1}}\right)^{r} .
\end{aligned}
$$

Applying the Cauchy's mean-value theorem to the left side of inequality (2.1), it turns out that there exists one point $\zeta \in(n, n+1)$ such that

$$
\begin{aligned}
& \frac{(n+2) a_{n+2}^{r}-(n+1) a_{n+1}^{r}}{(n+1) a_{n+1}^{r}-n a_{n}^{r}} \\
& \quad=\frac{F^{\prime}(\zeta)}{G^{\prime}(\zeta)} \geq\left(\frac{(n+1-\zeta) a_{n+1}+(\zeta-n) a_{n+2}}{(n+1-\zeta) a_{n}+(\zeta-n) a_{n+1}}\right)^{r} \geq\left(\frac{a_{n+2}}{a_{n+1}}\right)^{r},
\end{aligned}
$$

in which the logarithmic convexity of the sequence $\left\{a_{n}\right\}_{n=1}^{\infty}$ is used. Thus, the inequality (2.1) is proved. 
COROLLARY 2.3 [4]. Let $n$ and $m$ be natural numbers and $k$ a nonnegative integer. Then

$$
\frac{n+k}{n+m+k}<\left(\frac{(1 / n) \sum_{i=k+1}^{n+k} i^{r}}{(1 /(n+m)) \sum_{i=k+1}^{n+m+k} i^{r}}\right)^{1 / r},
$$

where $r$ is any given positive real number. The lower bound is best possible.

Proof. This follows from Corollary 2.2 applied to $a=(k+1, k+2, \ldots)$.

Note. When $k=0$ and $m=1$, inequality (2.20) reduces to (1.1).

NoTE. Recently, some inequalities related to Alzer's inequality and the sum of powers of positive integers or sequences have been proved. For details, see Qi [6, 5, 3], Sándor [9], and Qi and Luo [7].

ACKNOWLEDGEMENT. The work of the first author is supported in part by NSF of Henan Province (no. 004051800), SF for Pure Research of the Education Committee of Henan Province (no. 1999110004), and Doctor Fund of Jiaozuo Institute of Technology, China.

\section{REFERENCES}

[1] H. Alzer, On an inequality of H. Minc and L. Sathre, J. Math. Anal. Appl. 179 (1993), no. 2, 396-402. MR 94k:26021. Zbl 792.26008.

[2] N. Elezović and J. Pečarić, On Alzer's inequality, J. Math. Anal. Appl. 223 (1998), no. 1, 366-369. MR 99b:26033. Zbl 911.26013.

[3] F. Qi, An algebraic inequality, RGMIA Research Report Collection 2 (1999), no. 1, 81-83, Article 8. http://rgmia.vu.edu.au/v2n1.html.

[4] - Generalization of H. Alzer's inequality, J. Math. Anal. Appl. 240 (1999), no. 1, 294-297. CMP 1728191.

[5] __ Generalizations of Alzer's and Kuang's inequality, Tamkang Journal of Mathematics 31 (2000), no. 3, in press. RGMIA Research Report Collection 2 (1999), no. 6, Article 12. http://rgmia.vu.edu.au/v2n6.html.

[6] _ Inequalities and monotonicity of sequences involving $\sqrt[n]{(n+k) ! / k !}$, RGMIA Research Report Collection 2 (1999), no. 5, Article 8. http://rgmia.vu.edu.au/v2n5.html.

[7] F. Qi and Q. M. Luo, Generalization of H. Minc and J. Sathre's inequality, Tamkang Journal of Mathematics 31 (2000), no. 2, in press. RGMIA Research Report Collection 2 (1999), no. 6, Article 14. http://rgmia.vu.edu.au/v2n6.html.

[8] J. Sándor, On an inequality of Alzer, J. Math. Anal. Appl. 192 (1995), no. 3, 1034-1035. MR 96f:26026. Zbl 829.26013.

[9]___ Comments on an inequality for the sum of powers of positive integers, RGMIA Research Report Collection 2 (1999), no. 2, 259-261, http://rgmia.vu.edu.au.

[10] J. S. Ume, An elementary proof of H. Alzer's inequality, Math. Japon. 44 (1996), no. 3, 521-522. MR 97k:26021. Zbl 865.26016.

QI: DePartment of MATHematics, Jiaozuo Institute of TeChnology, JiAozuo City, HeNAN 454000, CHINA

E-mail address: qi feng@jzit.edu.cn

DEBNATH: DEPARTMENT OF MATHEMATICS, UNIVERSITY OF CENTRAL FLORIDA, ORLANDO, FLORIDA 32816, USA

E-mail address: 1debnath@pegasus.cc.ucf.edu 


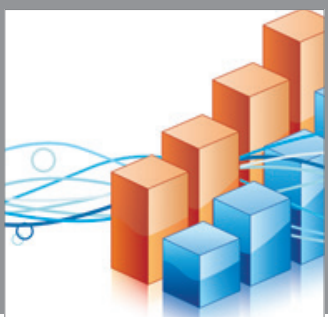

Advances in

Operations Research

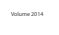

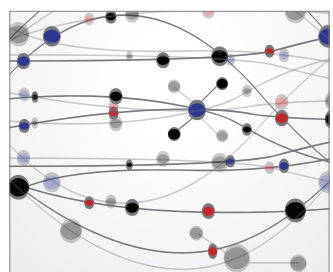

\section{The Scientific} World Journal
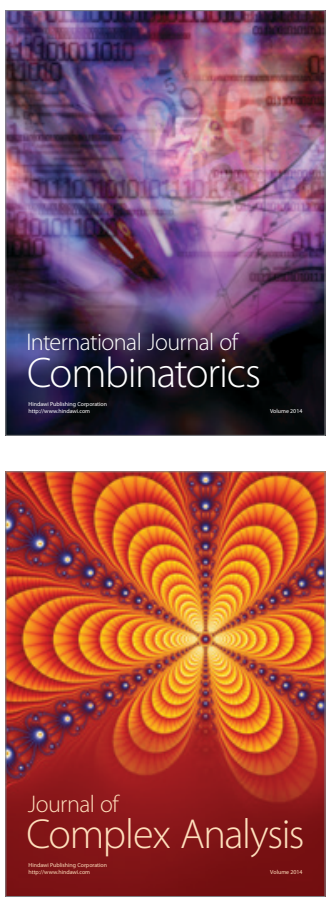

International Journal of

Mathematics and

Mathematical

Sciences
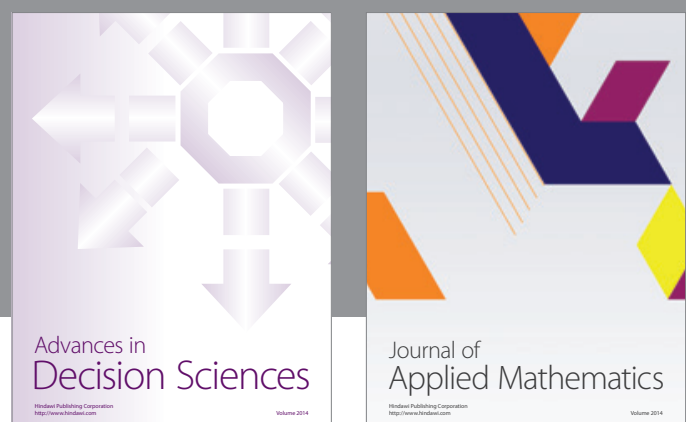

Journal of

Applied Mathematics
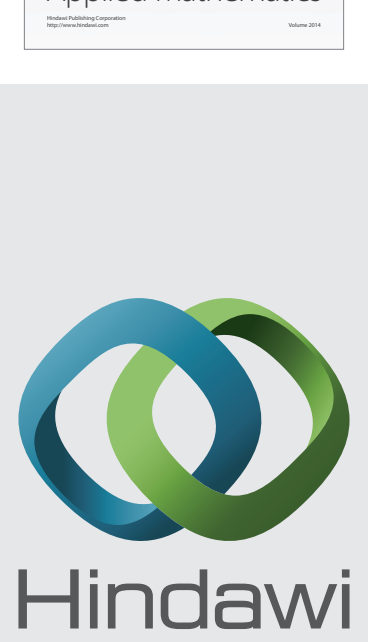

Submit your manuscripts at http://www.hindawi.com
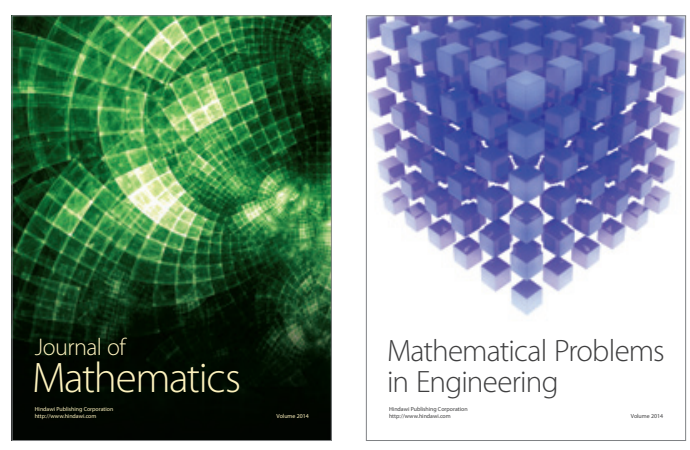

Mathematical Problems in Engineering
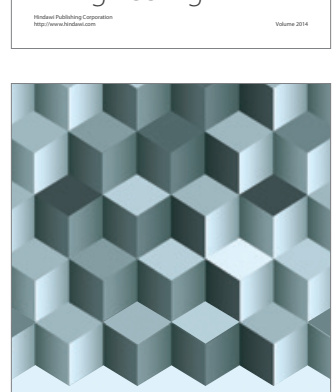

Journal of

Function Spaces
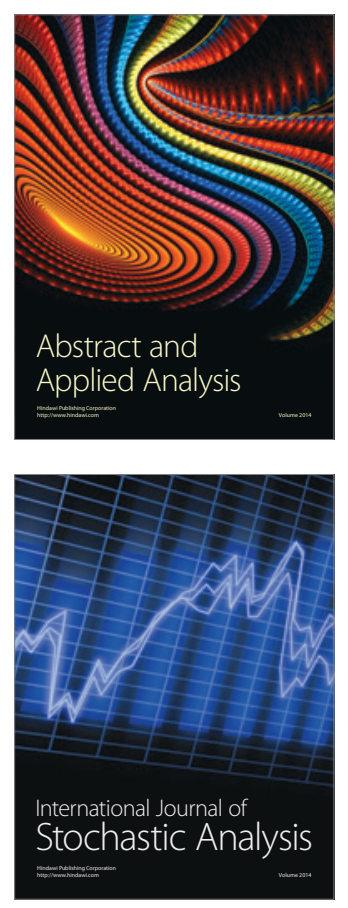

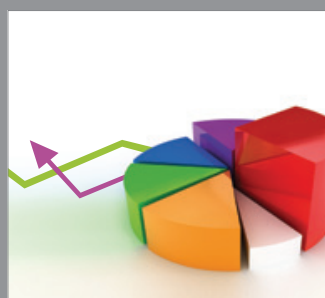

ournal of

Probability and Statistics

Promensencen
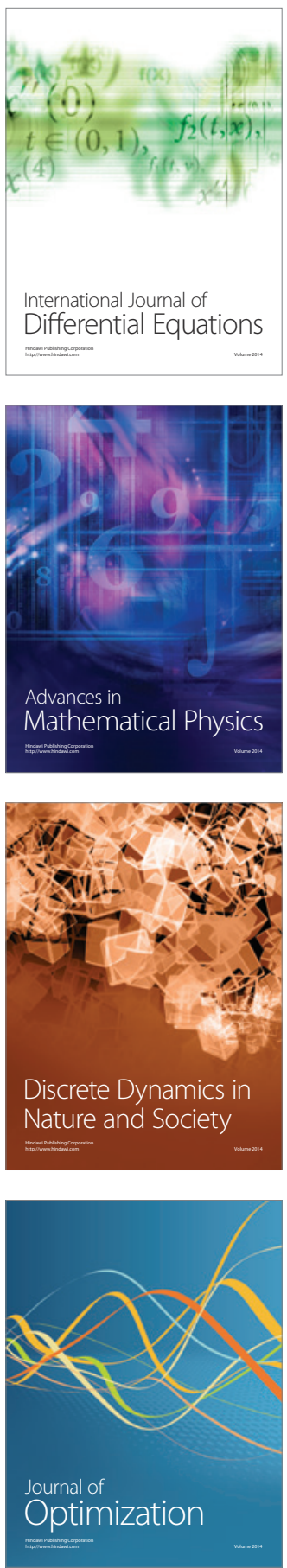